\title{
Endoscopic vs Conventional Septoplasty: A Comparative Study
}

Sandeep Kaushik, Siddharth Vashistha, Nitin Kumar Jain

\begin{abstract}
Objective: Traditional surgeries of the nasal septum improve the nasal airway but recent developments of endoscopic techniques have brought focus over several aspects of possible advantages over traditional techniques. These are due to better visualization and illumination, better accessibility and evaluation of exact pathology, lesser need of unnecessary manipulation, resection and overexposure of the septal framework and improving the scope for a revision surgery if required later.
\end{abstract}

Materials and methods: Sixty cases of deviated nasal septum (DNS) refractory to conservative medical treatment were divided into two groups of 30 patients and underwent correction surgery for nasal septal deformity using both endoscopic and conventional techniques.

Results: The postoperative follow-up was done at 1, 2, 4 weeks and 3 months. The clinical results of endoscopic septoplasty were found better as compared to conventional techniques with lesser complications and lesser period of hospitalization. However, the statistical analysis did not show a difference between the two groups.

Conclusion: The use of endoscopic techniques offers lesser complications and lesser period of hospitalization. However, this study of limited series needs further extensive evaluation to statistically establish the proposed results in future.

Keywords: Deviated nasal septum, Endoscopic, Septoplasty.

How to cite this article: Kaushik S, Vashistha S, Jain NK. Endoscopic vs Conventional Septoplasty: A Comparative Study. Clin Rhinol An Int J 2013;6(2):84-87.

Source of support: Nil

Conflict of interest: None declared

\section{INTRODUCTION}

At birth, the nasal septum is usually straight and remains straight in the childhood. As age progresses, there is a tendency for the septum to bend on one side or the other. Trauma during birth, including forceps placement or passage through a narrow pelvic canal, can cause injury that may lead to early septal deviation or to a deviation that is not evident until the more active growth phase of puberty. ${ }^{1}$

Septoplasty is a surgical procedure that corrects a deformity of the nasal septum. The usual purpose is to improve the nasal breathing. ${ }^{2}$

Lanza et al and Stammberger initially described the application of endoscopic techniques to the correction of septal deformity in 1991. Lanza et al described a detailed endoscopic approach to the treatment of isolated septal spurs. $^{3}$
When compared with standard head light technique endoscopic septoplasty provides important advantages which include adequate visualization, room for instrumentation during functional endoscopic sinus surgery, access to paranasal sinuses and for other surgeries like trans-septal approach to the sphenoid sinus, visualization and stoppage of postnasal bleeds. But before introduction of functional endoscopic sinus surgery, majority of septoplasties were done for nasal airway obstruction. ${ }^{4}$

Endoscopic septoplasty is a fast developing concept and gaining popularity with an increasing trend toward endoscopic surgeries. Furthermore in complex deformities, better correction is possible with the help of an endoscope since we can clearly see the posterior deviations. ${ }^{5}$

Patients undergoing traditional septoplasty require a longer stay due to bleeding or lip edema than those undergoing endoscopic septoplasty. Endoscope also aided limited resection and thus more conservation by guiding precise shaving of septal cartilage. ${ }^{6}$

Endoscopic septoplasty is a viable alternative to traditional headlight septoplasty with acceptable outcome and complications. ${ }^{7}$

In this prospective randomized study carried out at tertiary referral center, patients presenting with symptoms and signs of deviated nasal septum (DNS) were selected. Patients of gross nasal septal deviations were not included. The aim was to identify nasal septal pathology in relation to lateral nasal wall in a precise way, correct the pathology and to correlate the efficacy of endoscopic septoplasty with traditional approach.

\section{MATERIALS AND METHODS}

For the present study 60 cases of DNS were selected and underwent conventional and endoscopic septoplasty at our institution from December 2010 to August 2012.

Patients with DNS with or without septal spurs and those above the age of 18 years were included in the study.

Patient included into the study were divided into two groups, the control group which underwent conventional septoplasty and the study group which underwent endoscopic septoplasty.

Patients having acute rhinosinusitis, nasal polyps, malignancy, grossly deviated septum, revision cases and patients who did not follow-up for 3 months were excluded from our study. 
A detailed history regarding presenting complaints, history of present illness with special notes of presence or absence of symptoms, like nasal obstruction, nasal discharge, hyposmia, sneezing, nasal bleeding and postnasal drip were taken.

The detailed general physical examination and examination of nose, throat and ear were carried out. Detailed nasal endoscopic examination was done besides routine hematological tests, X-ray of paranasal sinusesWater's view were done if needed. If associated with chronic rhinosinusitis, noncontrast computerized tomogram with axial and coronal sections were done.

\section{Techniques for Conventional Septoplasty}

After infiltration with $2 \%$ xylocaine with adrenaline into columella and septum under headlight, incision (hemitransfixion incision) was made at caudal border. The mucoperichondrial and periosteal flaps were elevated upto perpendicular plate of ethmoid. The osseocartilaginous junction was dislocated. A $0.5 \mathrm{~cm}$ of the anterior margin of perpendicular plate of ethmoid was removed with Luc's forceps. An inferior cartilaginous strip of $0.5 \mathrm{~cm}$ was removed if necessary. The incision was closed using chromic catgut (3-0) and nasal packing was done.

\section{Techniques for Endoscopic Septoplasty}

Infiltration was given on the convex side over the most deviated part of septum using $0^{\circ} 4 \mathrm{~mm}$ endoscope. A vertical incision was made caudal to the deviation; also it was not extending from the dorsum to the floor as in classical incision but extended both superiorly and inferiorly just as needed to expose the most deviated part. If the cartilaginous septum is relatively straight and the deviation starts beyond the upper lateral cartilage, then a Killian's incision was performed just beyond this landmark. A submucoperichondrial flap was raised using suction elevator under direct visualization with the endoscope. The flap elevated was limited as it was raised from over the most deviated portion of nasal septum, i.e. posteriorly without disturbing the anterior normal septum. Septal cartilage was incised parallel but posterior to flap incision and caudal to the deviation. Endoscopic scissors were used to excise the deviated portion and the flap was repositioned back after suction clearance and edges of the incision were just made to lie closely without the need to suture and nasal packing was done.

\section{Postoperative Care}

Patients were given antibiotics and analgesics. They were discharged mostly after 24 hours except a few who required observation. After 2 days, three times a day regimen of saline-water flushing of the nose was initiated. Gentle nose blowing was permitted after the third week and strenuous exercise was discouraged for a total of 5 weeks. All patients were followed up in the outpatient on 7th, 15th, 30th and 90th days after the surgery and were assessed for subjective improvement.

Objective assessment was done by endoscopic examination and local examinations. The subjects of both groups were followed up and immediate as well as delayed results in terms of efficacy, benefits and postoperative complications were compared.

\section{RESULTS}

In our study of 60 patients with nasal septal deviations, major complaints were found to be of nasal obstruction (78.33\%), headache $(46.67 \%)$, nasal discharge $(36.6 \%)$ and nasal bleeding (16.67\%) (Table 1). These patients were divided into two groups who underwent septal surgery with two different techniques and the results were compared. All patients were followed up in the outpatient on 7th, 15th, 30th and 90th days after the surgery and were assessed for subjective improvement.

\begin{tabular}{|c|c|c|c|c|c|c|}
\hline \multirow[t]{2}{*}{ Age group (years) } & \multicolumn{2}{|c|}{$\begin{array}{c}\text { Group A } \\
\text { traditional } \\
\text { septoplasty }\end{array}$} & \multicolumn{2}{|c|}{$\begin{array}{c}\text { Group B } \\
\text { endoscopic } \\
\text { septoplasty }\end{array}$} & \multirow[t]{2}{*}{ Total } & \multirow[t]{2}{*}{$\%$} \\
\hline & No. & $\%$ & No. & $\%$ & & \\
\hline Nasal obstruction & 24 & 80 & 23 & 76.67 & 47 & 78.33 \\
\hline Headache & 14 & 46.67 & 14 & 46.67 & 28 & 46.67 \\
\hline Nasal discharge & 11 & 36.67 & 11 & 36.67 & 22 & 36.66 \\
\hline Nasal bleeding & 5 & 16.67 & 5 & 16.67 & 10 & 16.66 \\
\hline
\end{tabular}

The patients in group A had a mean age of 29.2 and a sex ratio of 2:1 whereas those in group B had a mean age of 28.6 and sex ratio of 2.75:1 (Table 2).

\begin{tabular}{|c|c|c|}
\hline & Control group & Endoscopic group \\
\hline Number of cases & 30 & 30 \\
\hline Mean age & 29.2 & 28.6 \\
\hline Sex ratio & $2: 1$ & $2.75: 1$ \\
\hline
\end{tabular}

The patients of both groups were assessed intraoperatively and for early and delayed complications which are shown in Table 3, there were clinically lesser complications seen in group B.

The results were analyzed by dividing them into objective and subjective improvements in both groups and are described in Tables 4 and 5. None of the group A patients with anterior deviation had residual deviation whereas in group B, 1 out of 10 patients $(10 \%)$ showed presence of 
residual deviation. Among posterior deviations patients, none of the patients of group B showed residual deviation whereas in group A, 1 out of 8 patients $(12.5 \%)$ showed residual deviation. Among patients with spur, none of the group B patients showed residual deviation whereas 1 out of 8 patients (12.5\%) of group A patients showed residual deviation. Also, lesser synechiae formation was seen in patients of group B as compared to that of group A(Table 4).

\begin{tabular}{lcccc}
\hline & \multicolumn{3}{c}{ Table 3: Complications } \\
& $\begin{array}{c}\text { Group A traditional } \\
\text { septoplasty }\end{array}$ & $\begin{array}{c}\text { Group B endoscopic } \\
\text { septoplasty }\end{array}$ \\
\cline { 2 - 5 } & No. & $\%$ & No. & $\%$ \\
\hline Hemorrhage & 3 & 10 & 1 & 3.33 \\
Mucosal tear & 3 & 10 & 2 & 6.67 \\
Hematoma & 4 & 13.33 & 0 & 0 \\
Synechiae & 3 & 10 & 1 & 3.33 \\
Residual deviation & 2 & 6.67 & 1 & 3.33 \\
Septal perforation & 2 & 6.67 & 0 & 0 \\
\hline
\end{tabular}

\begin{tabular}{lcc}
\multicolumn{2}{c}{ Table 4: Objective assessment in different types of } \\
Coviations \\
Complication & $\begin{array}{c}\text { Group } A \\
\text { traditional } \\
\text { septoplasty }\end{array}$ & $\begin{array}{c}\text { Group B } \\
\text { endoscopic } \\
\text { septoplasty }\end{array}$ \\
\hline Anterior deviations & $0 / 14$ & $1 / 10$ \\
Posterior deviations & $1 / 8$ & $0 / 12$ \\
Spur & $1 / 8$ & $0 / 8$ \\
Synechiae & & \\
Anterior deviations & $1 / 14$ & $1 / 10$ \\
Posterior deviations & $1 / 8$ & $0 / 12$ \\
Spur & $1 / 8$ & $0 / 8$ \\
\hline
\end{tabular}

After 90th day follow-up, patients with nasal obstruction showed more improvement in group B $(95.83 \%)$ as compared to group A $(82.60 \%)$, patients with headache also showed more improvement in group B $(92.85 \%)$ as compared to group A (79\%). Similarly, Nasal discharge $(90.9 \%)$ and nasal bleeding $(80 \%)$ were also more relieved in group B as compared to group A (Table 5).

\begin{tabular}{lcc}
\multicolumn{3}{c}{ Table 5: Postoperative symptoms relieved (subjective } \\
assessment)
\end{tabular}

Patients of group A required longer stay 20/30 (66.67\%) while in group B only $4 / 30$ (13.33\%) patients required longer stay. Statistically, a significant difference was seen between the two groups, it was seen that patients with endoscopic septoplasty had significantly shorter stay as compared to traditional septoplasty $(\mathrm{p}<0.0001)$ (Table 6).

\begin{tabular}{|c|c|c|}
\hline Duration (hours) & $\begin{array}{c}\text { Group A } \\
\text { traditional } \\
\text { septoplasty }\end{array}$ & $\begin{array}{c}\text { Group B } \\
\text { endoscopic } \\
\text { septoplasty }\end{array}$ \\
\hline$<48$ & $10(33.33 \%)$ & $26(86.67 \%)$ \\
\hline $48-72$ & $14(47 \%)$ & $4(13.33 \%)$ \\
\hline$>72$ & $6(20.00 \%)$ & $0(0.00 \%)$ \\
\hline
\end{tabular}

\section{DISCUSSION}

Our study showed better results and lesser complications in endoscopic septoplasty as compared to traditional septoplasty group as endoscope gives better illumination and improved access to high DNS and allowed limited incision, limited flap elevation and achieves correction with least resection. This technique causes lesser trauma to the septum, thus reducing the postoperative complications.

Study of Gupta, Motwani (2005) shows that complication rates were significantly more in traditional group. In our study, more complications in group $\mathrm{A}$ is in agreement with the mentioned study but it did not attain any statistical significance $(p>0.05){ }^{6}$

The study of Gupta, Motwani (2005) and Nayak et al (1998); both study showed that traditional group patients required longer stay due to bleeding or lip edema which is in agreement with the present study and was found to be statistically significant. ${ }^{6,8}$

In endoscopic group of patients, more improvement in the posterior deviations and spurs was seen in comparison to traditional group of patients. The study of Nayak et al (1998) showed that only about $10 \%$ patients of anterior deflection had persistent septal deformity and posterior deviations/ spurs were effectively corrected in most of the cases. This study also showed that endoscope-aided septoplasty was found to be more effective in treating symptoms, such as nasal obstruction and headache. ${ }^{8}$

\section{REFERENCES}

1. Bhattacharjee A, Uddin S, Purkaystha P. Deviated nasal septum in the newborn - a 1-year study. Indian J Otolaryngol Head Neck Surg 2005 Oct;57(4):304-308.

2. Siegel NS, Gliklich RE, Taghizadeh F, Chang Y. Outcomes of septoplasty. Otolaryngol Head Neck Surg 2000 Feb;122(2): 228-232.

3. Lanza DC, Kennedy DW, Zinreich SJ. Nasal endoscopy and its surgical application. Essential otolaryngology: head and neck surgery. 5th ed. New York: Medical examination; 1991. p. 373-387.

4. Cantrell H. Limited septoplasty for endoscopic sinus surgery. Otolaryngol Head Neck Surg 1997 Feb;116(2):274-277.

5. Gupta N. Endoscopic septoplasty. Indian J Otolatyngol Head Neck Surg 2005 Jul;57(3):240-243.

6. Gupta M, Motwani G. Comparative study of endoscopic aided septoplasty and traditional septoplasty in posterior nasal septa deviations. Indian J Otolaryngol Head Neck Surg 2005 Oct;57(4):309-311. 
7. Chung BJ, Batra PS, Citardi MJ, Lanza DC. Endoscopic septoplasty: revisitation of the technique, indications and outcomes. Am J Rhinol 2007 May-Jun;21(3):307-311.

8. Nayak DR, Balakrishnan R, Murthy KD. An endoscopic approach to the deviated nasal septum--a preliminary study. J Laryngol Otol 1998 Oct;112(10):934-999.

\section{ABOUT THE AUTHORS}

\section{Sandeep Kaushik}

Associate Professor and Head, Department of Otorhinolaryngology GSVM Medical College, Kanpur, Uttar Pradesh, India
Correspondence Address: House No. L-25, GSVM Campus Kanpur-208002, Uttar Pradesh, India, Phone: 9935015199, e-mail: dockaushik@gmail.com

\section{Siddharth Vashistha}

Postgraduate Student, Department of Otorhinolaryngology, GSVM Medical College, Kanpur, Uttar Pradesh, India

\section{Nitin Kumar Jain}

Postgraduate Student, Department of Otorhinolaryngology, GSVM Medical College, Kanpur, Uttar Pradesh, India 